\title{
SOME ASPECTS OF NITROGEN MINERALIZATION IN SOIL UNDER FALLOW AND WHEAT
}

\author{
P. B. S. HART \\ (M.Agr.Sc., Lincoln College, University of Canterbury)
}

The nature of net soil nitrogen mineralization and its implications in soil under fallow and wheat were investigated in field and pot experiments.

It was found that the presence of wheat significantly enhanced net soil nitrogen mineralization compared with soil under fallow. In the field, this depended on the stage of wheat growth, commencing only after sufficient root development had occurred, and continuing to the booting stage, This was considered to result from greater soil microbial activity in the rhizosphere of wheat, and the continuous removal of soil inorganic nitrogen by wheat roots from the soil pool, It was not related to differences in soil heat accumulation and moisture content between fallow and wheat.

The soil inorganic nitrogen levels followed a seasonal pattem, decreasing over the winter and early spring, and increasing over late spring and summer. There was no apparent lag in net soil nitrogen mineralization under fallow in the spring compared with that under wheat.

Under growth cabinet conditions, the response of microbial populations to some moisture treatments differed in soil under fallow and wheat. Increases in daytime temperature of $7^{\circ} \mathrm{C}$ from $17^{\circ} \mathrm{C}$ did not effect net soil nitrogen mineralization. Under fallow, different sequences of fluctuating temperatures also, showed no effect.

In the field, rates of nitrogen mineralization were 3.3 and $2.0 \%$ in soil under fallow and wheat, respectively. The difference was accounted for by the greater frequency of sampling in the soil under fallow.

Significant linear and quadratic relationships were obtained in relating changes in ammonium, nitrate and total inorganic nitrogen levels to some measured environmental variables (soil heat accumulation, initial soil moisture content, changes in soil moisture content and rainfall). The maximum coefficient of determination obtained was 37\% for the change in nitrate nitrogen in the $\mathrm{O}-10 \mathrm{~cm}$ soil depth under fallow.

The mean rate of nitrification increased with increasing depth of soil sampled under fallow. Nitrifier numbers did not change over the same sampling period when large changes in total inorganic nitrogen occurred. Thus the use of nitrifier numbers as a measure of the rate of ammonium formation is unreliable.

Decreases in the size of the inorganic soil nitrogen pool occurred in the winter and early spring period. This derease was probably due to leaching losses. However, it was not possible to confirm this by the use of tension-plant lysimeters because large variations in volumes of soil water collected were obtained. These variations were nrobablv due to lateral movement of soil water resulting from the lithological discontinuity of the soil profile at the lower depths.

A mathematical model of soil nitrogen transformations was developed and found to give satisfactory agreement between the predicted and actual experimental data. 